\title{
Diseño de un aplicativo web para la enseñanza del
} idioma kichwa

\author{
Design of a web application for teaching the Kichwa language
}

Design de um aplicativo da Web para o ensino da língua Kichwa

\author{
Byron Buitrón Cachipuendo \\ Universidad de Otavalo, Ecuador \\ e_babuitron@uotavalo.edu.ec \\ https://orcid.org/0000-0003-3906-1444 \\ Lidia Inés Díaz Gispert \\ Universidad de Otavalo, Ecuador \\ ldiaz@uotavalo.edu.ec \\ https://orcid.org/0000-0002-3781-0483 \\ José A. Cahuasquí Anrango \\ Universidad de Otavalo, Ecuador \\ jcahuasqui@uotavalo.edu.ec \\ https://orcid.org/0000-0002-2212-3429
}

\section{Resumen}

La era de la globalización trajo consigo el incremento de la urbanización, pero también la desmotivación por los conocimientos, ciencias y saberes tradicionales de los pueblos y nacionalidades indígenas del Ecuador, como sucede con el idioma kichwa. Sin embargo, el uso de las nuevas tecnologías de la información y comunicación también se pueden usar para potenciar el proceso de enseñanza y aprendizaje, si se adaptan diferentes elementos formales y constitutivos del mensaje gráfico que pueden ayudar a la estética y funcionalidad de un producto web para fortalecer la cultura y la aceptación de la enseñanza de un idioma ancestral. La Universidad de Otavalo se encuentra ubicada en el cantón Otavalo, llamada capital intercultural del Ecuador por su riqueza cultural e histórica y por ser el lugar de origen del pueblo kichwa Otavalo. Teniendo en cuenta el contexto sociocultural y etnográfico poblacional de la localidad donde se asienta la 
institución, el objetivo de esta investigación fue diseñar un aplicativo web para el proceso de enseñanza y aprendizaje del idioma kichwa unificado, para lo cual se contó con una serie de recursos multimedia que permitieron su visualización y escucha, apoyados en el modelo educativo de la Universidad de Otavalo y brindando una herramienta pedagógica en línea que puede proporcionar al docente la motivación para enseñar y al estudiante el interés por aprender, alcanzando la aceptación de la enseñanza de un idioma ancestral que identifica a una nacionalidad. Las bases metodológicas del estudio se corresponden con una investigación descriptiva no experimental; se aplicaron encuestas a una muestra de 70 estudiantes de la Universidad de Otavalo, de una población de 98, que cursan la asignatura Kichwa I y Kichwa II. Fue conveniente para este estudio utilizar una confiabilidad de $95 \%$ para el cálculo del percentil correspondiente a la distribución normal, con un error máximo permisible igual a 0.05 , mientras que la proporción muestral estimada, al no tener investigaciones anteriores que permitieran preestablecer este valor, fue considerada de $50 \%$, lo que además garantiza el máximo tamaño muestral. La fiabilidad de la encuesta medida a través del coeficiente alfa de Cronbach fue de 0.798, por lo que puede considerarse alta. Como resultado se obtuvo el diseño de un aplicativo web para contribuir al logro de una enseñanza básica, clara y amena del idioma kichwa, teniendo en cuenta que no existen suficientes estudios de alcance institucional sobre su aprendizaje y sus medios de enseñanza, valorizando el idioma y despertando el interés de los estudiantes, así como satisfaciendo la demanda de horas en la malla curricular, según criterio de los docentes de la universidad.

Palabras clave: diversidad cultural, idioma ancestral, malla curricular, oferta educativa, recurso didáctico interactivo

\section{Abstract}

The era of globalization brought with it the increase in urbanization, and this in turn the demotivation of the traditional knowledge, science and knowledge of the indigenous peoples and nationalities of Ecuador, such is the case of the Kichwa language. However, the use of new information and communication technologies stimulated the teachinglearning process, adopting different formal and constitutive elements of the graphic message, which helped the aesthetics and functionality of a web product, to prevent and strengthen culture and acceptance of the teaching of an ancestral language. The University of Otavalo is located in the Otavalo canton, called the Intercultural Capital of Ecuador, for its cultural and historical richness, and for being the place of origin of the Kichwa 
Otavalo people. Taking into account the socio-cultural and ethnographic population context of the town where the institution is located, the objective of this research was to design a web application for the unified teaching-learning process of the Kichwa language, with a series of multimedia resources that allowed its visualization and listening, supported by the Educational Model of the University of Otavalo, providing an online pedagogical tool that provides the teacher with the motivation to teach and the student with the interest in learning, reaching acceptance of the teaching of an ancestral language, which identifies a nationality. The methodological bases of the study correspond to a non-experimental descriptive research, where surveys were applied to a sample of 70 students from the University of Otavalo, out of a population of 98, who study Kichwa I and Kichwa II. It was convenient for this study to use a reliability of $95 \%$ to calculate the percentile corresponding to the normal distribution, with a maximum permissible error equal to 0.05 , while the estimated sample proportion, as there was no previous research that allowed to preset this value, was considered $50 \%$, which also guarantees the maximum sample size. The reliability of the survey measured through Cronbach's Alpha Coefficient was 0.798, so it can be considered high. Thus, the result was the design of a web application to contribute to the achievement of a basic education in a clear and enjoyable way of the Kichwa language, taking into account that there are not enough studies of institutional scope on its learning and its teaching aids valuing the language and awakening the interest of students, as well as satisfying the demand for hours in the curriculum, according to the criteria of the university teachers.

Keywords: cultural diversity, ancestral language, curricular mesh, educational offer, interactive teaching resource

\section{Resumo}

A era da globalização trouxe consigo um aumento da urbanização, que por sua vez foi desmotivada pelos saberes, ciências e saberes tradicionais dos povos indígenas e nacionalidades do Equador, como é o caso da língua Kichwa. No entanto, o uso de novas tecnologias de informação e comunicação estimulou o processo de ensino-aprendizagem, adotando diferentes elementos formais e constitutivos da mensagem gráfica, que auxiliam na estética e na funcionalidade de um produto web, para prevenir e fortalecer a cultura e aceitação do ensino de uma língua ancestral. A Universidade de Otavalo está localizada no cantão de Otavalo, chamada Capital Intercultural do Equador, por sua riqueza cultural e histórica, e por ser o local de origem do povo Kichwa Otavalo. Levando em 
consideração o contexto sociocultural e etnográfico da população do município onde a instituição está inserida, o objetivo desta pesquisa foi desenhar uma aplicação web para o processo de ensino-aprendizagem da língua Kichwa unificada, com uma série de recursos multimídia que permitissem A sua visualização e escuta, apoiada no Modelo Educacional da Universidade de Otavalo, proporcionando uma ferramenta pedagógica online que proporciona ao professor a motivação para ensinar e ao aluno o interesse em aprender, alcançando a aceitação do ensino de uma língua ancestral, que identifica uma nacionalidade. As bases metodológicas do estudo correspondem a uma pesquisa descritiva não experimental, onde foram aplicados inquéritos a uma amostra de 70 alunos da Universidade de Otavalo, numa população de 98, que estudam Kichwa I e Kichwa II. Foi conveniente para este estudo utilizar uma confiabilidade de 95\% para calcular o percentil correspondente à distribuição normal, com erro máximo admissível igual a 0,05, enquanto a proporção amostral estimada, pois não houve pesquisas anteriores que permitissem predefinir este valor, foi considerado 50\%, o que também garante o tamanho máximo da amostra. A confiabilidade da pesquisa medida por meio do Coeficiente Alfa de Cronbach foi de 0,798 , portanto, pode ser considerada alta. Assim, o resultado foi o desenho de uma aplicação web para contribuir para a realização de uma educação básica de forma clara e divertida da língua Kichwa, tendo em vista que não há estudos de âmbito institucional suficientes sobre sua aprendizagem e seus auxiliares de ensino valorizando a língua e despertando o interesse dos alunos, bem como atendendo à demanda de horas do currículo, segundo os critérios dos professores universitários.

Palavras-chave: diversidade cultural, linguagem ancestral, malha curricular, oferta educacional, recurso didático interativo.

Fecha Recepción: Abril 2020

Fecha Aceptación: Noviembre 2020

\section{Introducción}

Ecuador es uno de los países pertenecientes a la cordillera andina, y se caracteriza por su diversidad cultural y étnica. Desde la conquista de los Incas ha heredado riquezas culturales, una de ellas el idioma kichwa, que se ha venido transmitiendo de generación en generación por las comunidades indígenas. Sin embargo, la dominación española, el mestizaje y la globalización han generado que poco a poco se vaya disipando su cultura, siendo una manifestacion de este proceso la pérdida del idioma kichwa (Pichazaca, 2017). 
La Constitución de la República reconoce al Estado ecuatoriano como “intercultural, pluricultural y multilingue. Abarca en su relativamente pequeño territorio, 14 nacionalidades indígenas y 13 lenguas". Una de las lenguas más representativas de este país es el kichwa, lo que permite la integración de nuevos sistemas de educación que garanticen el cumplimiento de los derechos dentro de una "visión intercultural acorde con la diversidad geográfica, cultural y lingüística del país, y el respeto a los derechos de las comunidades, pueblos y nacionalidades" (Constitución Política de la República del Ecuador, Artículos 66, 68, 69 y 84, numeral 11, 2008).

El idioma kichwa se habla en el callejón interandino desde el norte de Imbabura hasta el sur de la provincia de Loja, y en el oriente ecuatoriano en las provincias de Napo, Orellana, Pastaza, Morona Santiago y Zamora Chinchipe (Mejeant, 2001). Como sostiene (Álvarez y Montaluisa, 2017), según el censo de población realizado en el año 2010, existe un total de 591448 hablantes kichwa a nivel nacional, con presencia en la mayoría de las provincias del país, excepto en Carchi, Esmeraldas, Manabí y Morona Santiago. También existen poblaciones migrantes que se asentaron hace muchos años en Guayas, El Oro, Los Ríos y Galápagos.

Ilvis (2018) certifica que "la riqueza cultural de las nacionalidades ecuatorianas es evidente en cada una de las regiones"; pese a ello, Ecuador no ha logrado materializar una oferta educativa que responda a las demandas de sostenibilidad cultural de estas. El Ministerio de Educación del Ecuador (2009) plantea que la revalorización de las lenguas ancestrales en el Ecuador es una tarea muy ardua, que depende de factores como la implementación de políticas lingüísticas que visibilicen y empoderen a los pueblos indígenas, el cambio de actitud en las familias, de manera que enseñen con orgullo su lengua a los hijos. "Siempre que sea viable, deberá enseñarse a los niños de los pueblos interesados a leer y a escribir en su propia lengua indígena o en la lengua que más comúnmente se hable en el grupo a que pertenezcan" (Convenio Núm. 169 de la Organización Internacional del Trabajo [OIT], sobre pueblos indígenas y tribales, Declaración de Naciones Unidas sobre los derechos de los pueblos indígenas, 2014, p. 130)

Según Lema (1997, p. 7), el idioma "es considerado como un instrumento de comunicación, por tanto su enseñanza debe consistir en capacitar al pueblo para una apropiada y eficaz comunicación, ya sea en forma oral o por escrito". Sin embargo: 
La lengua cae en desuso por motivos de racismo y marginación social, pero también porque no es hablada por los blancos-mestizos, con quienes los indígenas interaccionan en los mercados y en los contextos similares, ni tampoco es lengua de uso común en las instituciones del Estado, los bancos u otras entidades (Rodríguez, 2018, p. 119).

"Enseñar el idioma kichwa plantea una necesidad didáctica de transferir el conocimiento, de una manera creativa para las nuevas generaciones" (Buitrón, 2019, p. 3). Los modelos de enseñanza basados en las TIC, tales como el electronic learning ( $E$ learning) y el blended learning (B-learning), están generando nuevos ambientes de aprendizaje (virtuales) que buscan que el estudiante se encuentre constantemente motivado, mediante la utilización de novedosas estrategias y recursos que proporcionan los elementos para unas formas de comunicación en nuevas y diversas situaciones didácticas (Salinas, 1997).

El E-learning es una modalidad educativa totalmente a distancia; se desarrolla a través de la creación de ambientes virtuales flexibles, abiertos e interactivos; dispone de todos los materiales necesarios para el aprendizaje del estudiante e integra elementos interactivos de comunicación tales como foros, chat, videoconferencias, multimedia, videos, presentaciones y documentos que guían el desarrollo cognitivo. Posee una serie de características que la hacen una modalidad de enseñanza innovadora, en la que el usuario sólo necesita tener conocimientos básicos sobre el manejo de computadoras personales e Internet; dándole la oportunidad de acceder a la información desde cualquier parte del mundo, sin importar la hora (Rojas y Bolívar, 2009).

Quispe Yucra, Urrelo Valdivia, Morales Muraña y Cariman Davis (2012) plantean la importancia del uso de las tecnologías de la información y comunicación dentro del proceso de enseñanza aprendizaje del idioma kichwa, alternativa para el desarrollo de esta lengua materna. Declaran que el uso de nuevas tecnologías en la revitalización de los idiomas indígenas posee ventajas, porque otorga un estatus social a la lengua y la incluye en los medios modernos. Además, permite a los estudiantes crear sus propios materiales y subirlos a las redes sociales. El uso de la tecnología favorece que la enseñanza de las lenguas sea más interesante y dinámica, al desarrollarse procesos que proporcionan la percepción del aprendizaje, así como del autoaprendizaje, permitiendo a los estudiantes volver a lo aprendido las veces que su curiosidad lo estime necesario. Igualmente, el 


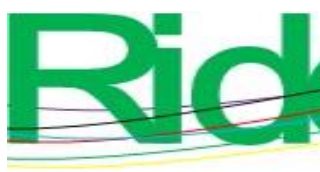

docente busca nuevas estrategias y se apoya en recursos tecnológicos didácticos para llegar a los estudiantes, quienes haciendo uso de plataformas digitales, acceden a herramientas educativas para su formación.

El hecho de que el idioma kichwa sea hablado por una población históricamente subalterna ha generado actitudes diglósicas (situación de convivencia de dos variedades lingüísticas, donde una es dominante) de parte del sector de docentes y estudiantes mestizos, dando como consecuencia la desmotivación intrínseca no solamente de los estudiantes monolingües, sino también de los bilingües kichwa hablantes. Por eso, resulta importante emprender procesos de animación al estudio del idioma kichwa (Camas, 2016).

La Oficina Regional de Educación para América Latina y el Caribe (2013) afirma: Los sistemas educativos están llamados a vivir cambios paradigmáticos en su actual configuración, y este proceso será facilitado y acelerado por el apoyo que presten las TIC para su desarrollo. La educación del siglo XXI, para desarrollar estas competencias en cada uno de sus estudiantes, requiere de una nueva forma de escuela, más flexible, personalizada y ubicua. (p. 32).

Según Sunkel y Trucco (2012), América Latina se ha convertido en una de las regiones más proactivas del mundo en relación con la integración de las TIC en sus sistemas educativos, con el fin de contribuir a la inclusión social, la democratización y la reducción de la brecha digital.

Siendo así, se establece la siguiente interrogante general de investigación: ¿cómo contribuir al fortalecimiento del proceso de enseñanza aprendizaje de la lengua kichwa en la Universidad de Otavalo? Por tanto, teniendo en cuenta el contexto sociocultural y etnográfico poblacional de la localidad donde se asienta la institución educativa, se estableció como objetivo diseñar un aplicativo web que fortalezca el proceso de enseñanza y aprendizaje del idioma kichwa en la Universidad de Otavalo.

\section{Descripción de un aplicativo web}

Según Mendoza y Barrios (2004)

Una aplicación web consiste en un software basado en internet, en el cual una población de usuario, por medio de un navegador, hacen peticiones remotas y esperan una respuesta que puede implicar una mezcla de publicación impresa y desarrollo de software, de mercadeo e informática y relaciones externas, y de arte y tecnología (p. 81). 
La tecnología que permite que funcione una aplicación web es el internet (canal), y el soporte que plasma la información es la computadora; la aplicación se ejecuta en el navegador web (medio) cuando es accedido a una URL. "Con una aplicación web la experiencia de usuario será dinámica por el diseño adaptado y sobre todo, por estar desarrollada en un lenguaje para un sistema operativo en concreto” (Buitrón, 2019, p. 27). La aplicación puede ser desarrollada con un solo lenguaje de programación, como el HTML, JavaScript o CSS (Montiel, 2017).

Las aplicaciones web enfocadas al aprendizaje se usan como transmisores de conocimientos y noticias. En estas aplicaciones web se privilegia el acceso al contenido; por este motivo, la usabilidad y accesibilidad son fundamentales (Cuello y Vittones, 2014).

Existen diferentes programas para el diseño de un aplicativo web, uno de ellos es Adobe XD. Según su página web oficial (Adobe, 2020), se aclara que este programa ayuda a "crear aplicaciones móviles interactivas y prototipos de sitios web con facilidad. Puedes crear y compartir diseños para sitios web, aplicaciones móviles, interfaces de voz, juegos y mucho más" (p.1). Este programa ofrece la posibilidad de crear mesas de trabajo tomando en cuenta las dimensiones para el dispositivo que pretende usar el aplicativo. Al ser un aplicativo web, su resolución es de "web 1366 (1366px*768p)".

\section{Estructura gramatical del idioma kichwa}

Cuando se habla un idioma determinado se utilizan ciertos sonidos que corresponden a esa lengua, y no a otra; por ejemplo, en el español hay ciertos sonidos diferentes entre el hablado en España y en Argentina, es decir, existe fonología (Gómez et al., 2005). Los fonemas como unidades distintivas en su manifestación oral, en el habla cotidiana, se expresan de maneras distintas (propio de las lenguas vivas) según la lengua, la edad, la zona geográfica, el estatus y la época de su manifestación (Yachakukkunapa shimiyuk kamu, 2009).

En el caso del idioma kichwa, se enseña la correcta pronunciación de las palabras, pero en lo que respecta a las variantes de la pronunciación en la comunicación oral, casi resulta irrealizable registrarlas todas y a cada una de ellas con sus características; aquí se presentan algunas de las más recurrentes (tabla 1): 
Tabla 1. Algunas variaciones de la pronunciación del idioma kichwa

\begin{tabular}{|c|c|c|c|}
\hline \multirow{2}{*}{} & \multicolumn{3}{|c|}{ LETRAS Y SU PRONUNCIACIÓN } \\
\cline { 2 - 4 } & Se escribe & Se pronuncia & Traducción \\
\hline $\begin{array}{c}\text { La "K" cuando } \\
\text { va después de la } \\
\text { consonante "N" } \\
\text { se pronuncia } \\
\text { como "G" }\end{array}$ & punku & pungu & puerta \\
\cline { 2 - 4 } & panka & fanga & hoja \\
\hline $\begin{array}{c}\text { La "LL" es } \\
\text { pronunciada } \\
\text { como "L" }\end{array}$ & warmi atallpa & warmi atalpa & gallina \\
\cline { 2 - 4 } & allpa & alpa & tierra \\
\hline
\end{tabular}

Fuente: Elaboración propia

Las palabras que se utilizan están formadas por elementos más pequeños, que combinados sirven para formarlas. La parte de la gramática que estudia este fenómeno es la morfología (Gómez et al., 2005) (tabla 2):

Tabla 2. Estructura de las palabras para una oración

\begin{tabular}{|c|c|c|}
\hline \multicolumn{3}{|c|}{ ESTRUCTURA DE LAS PALABRAS } \\
\hline Juan & come & manzanas \\
\hline nombre & verbo & sustantivo \\
\hline
\end{tabular}

Fuente: Elaboración propia

En kichwa la morfología enseña la clasificación de las palabras, de acuerdo con la función que desempeñan en la oración. Por medio de las partículas aglutinantes que se intercalan entre la raíz y la terminación o se posponen a las palabras, se obtienen otros nombres, que son adjetivos, verbos y adverbios, o también se cambia el significado sin cambiar la constitución primitiva (Lema, 1997). Seguidamente se dan ejemplos de partículas aglutinantes combinando la palabra maki que significa 'mano'. (tabla 3): 
Tabla 3. Raíz y partículas aglutinantes

\begin{tabular}{|c|c|}
\hline \multicolumn{2}{|c|}{$\begin{array}{c}\text { DIVERSAS FUNCIONES Y } \\
\text { SIGNIFICADOS }\end{array}$} \\
\hline $\begin{array}{c}\text { palabra }+ \\
\text { partícula } \\
\text { aglutinante }\end{array}$ & significado \\
\hline Maki & Mano \\
\hline Makiwan & con la mano \\
\hline Makikaman & hasta la mano \\
\hline Makiman & a la mano \\
\hline Makipi & en la mano \\
\hline Makimanta & de, desde la mano \\
\hline Makipura & entre las manos \\
\hline Makipak & de la mano \\
\hline Makikuna & Manos \\
\hline
\end{tabular}

Fuente: Elaboración propia

Se habla con palabras, pero esas palabras necesitan organizarse según ciertas reglas. La parte de la gramática que se ocupa de las reglas que rigen para estructurar las oraciones gramaticales se denomina sintaxis (Gómez et al., 2005). Es el estudio de la estructura interna de la oración (tabla 4):

Tabla 4. Estructura de las palabras en un oración

\begin{tabular}{|c|c|c|}
\hline \multicolumn{3}{|c|}{ ESTRUCTURA DE LA ORACIÓN } \\
\hline Juan & come & manzanas \\
\hline sujeto & predicado & complemento \\
\hline
\end{tabular}

Fuente: Elaboración propia

En kichwa, la sintaxis es distinta a la del castellano no solo por las partículas aglutinantes, sino también por la formación y la concordancia en las oraciones. Según la finalidad comunicativa y práctica del hablante, cada uno de los componentes de la oración varía de lugar; es decir, primero va el sujeto, luego el complemento y finalmente el predicado (Instituto de Idiomas, Ciencias y Saberes Ancestrales, 2016) (tabla 5): 
Tabla 5. Estructura de las palabras en un oración kichwa

\begin{tabular}{|c|c|c|}
\hline \multicolumn{3}{|c|}{ ESTRUCTURA DE LA ORACIÓN } \\
KICHWA \\
\hline Juan & come & manzanas \\
\hline sujeto & complemento & predicado \\
\hline
\end{tabular}

Fuente: Elaboración propia

\section{Pasos para el aprendizaje del kichwa nivel básico}

Es muy importante empezar hablando en kichwa desde el primer momento, motivo por el cual se sugiere conocer, practicar y autoevaluarse constantemente. Cahuasquí (2019, sin publicar) considera los siguientes pasos a seguir:

\section{Conocer alfabeto kichwa}

Un alfabeto está formado por los símbolos (vocales y consonantes) que se utilizan en el marco de un sistema que permite la comunicación oral o escrita. Al alfabeto se le considera como sinónimo de abecedario porque tiene una sucesión de letras de un lenguaje. El alfabeto latino consta de 26 letras principales, comienza por la A y termina en la Z (Pérez y Merino, 2017).

El cuadro alfabético del idioma kichwa, aunque aprobado por la dirección de Educación Intercultural Bilingüe (DINEIB) con 20 grafías (3 vocales y 17 consonantes), es un tema abierto debido a que las grafías $t s$ y $z$ son utilizadas en ciertas localidades como la provincia de Imbabura para ciertas palabras prekichwas (tabla 6):

Tabla 6. Vocales y consonaste del alfabeto kichwa

\begin{tabular}{|c|}
\hline VOCALES \\
\hline $\mathrm{a}, \mathrm{i}, \mathrm{u}$ \\
\hline CONSONANTES \\
\hline $\mathrm{ch}, \mathrm{h}, \mathrm{k}, \mathrm{l}, \mathrm{ll}, \mathrm{m}, \mathrm{n}, \tilde{\mathrm{n} n}, \mathrm{p}, \mathrm{r}, \mathrm{s}, \mathrm{sh}, \mathrm{t}, \mathrm{ts}, \mathrm{w}, \mathrm{y}, \mathrm{z}$ \\
\hline Fuente: Elaboración propia \\
\hline
\end{tabular}

La oficialización definitiva del alfabeto kichwa se da el 16 de septiembre de 2004 bajo el Acuerdo Ministerial n. ${ }^{\circ}$ 244, siendo este reconocimiento fruto de un arduo trabajo de actores educativos, lingüistas, organizaciones indígenas, entre otras, admitiendo la utilización de la grafía $h$ en vez de la j, quedando establecido de la siguiente forma: a, ch, i , h, k, l, ll, m, n, ñ, p, r, s, sh, t, (“'ts”), u, w, y (z) (Cahuasquí , 2017, sin publicar). 
Las grafías que forman el alfabeto al constituirse en una palabra tienen acento prosódico de graves, lo que quiere decir que al momento de aglutinar una palabra, el acento de voz recorrerá hasta la penúltima sílaba para el cumplimiento de esta regla. Que el idioma kichwa es aglutinante significa que a partir de una palabra base o su raíz se pueden crear nuevas composiciones con la adhesión de los morfemas, obteniendo como resultado nuevos significados (Cahuasquí, 2019, sin publicar).

\section{Conocer verbo y la conjugación}

El verbo es la palabra que expresa acción, y en castellano esos vocablos terminan en -ar, -er, -ir. Esto significa que cualquier verbo está dividido en dos partes: la raíz verbal y terminación verbal. En el idioma kichwa, todos los verbos tienen una única terminación, que es -na (Paza, 2011) (tabla 7).

Tabla 7. Comparación de la estructura del verbo en castellano y kichwa

\begin{tabular}{|c|c|}
\hline \multicolumn{2}{|c|}{ VERBO } \\
\hline en castellano & en kichwa \\
\hline ar - er - ir & $\mathrm{Na}$ \\
\hline \multicolumn{2}{|c|}{ ejemplo verbo } \\
\hline vivir & Kawsana \\
\hline caminar & Purina \\
\hline comer & Mikuna \\
\hline raíz verbal + \\
terminación verbal & terminación verbal + \\
\hline viv + ir & kawsa + na \\
\hline camin + ar & puri + na \\
\hline com + er & miku + na \\
\hline
\end{tabular}

Fuente: Elaboración propia

En kichwa, independientemente de cualquier tiempo, hay una sola forma de conjugar los verbos. La raíz permanece invariable en todos los modos, tiempos y personas. Para la conjugación de un verbo se necesita un pronombre, la raíz verbal y la terminación del tiempo (Paza, 2011) (tablas 8 y 9): 
Tabla 8. Pronombres en castellano y kichwa

\begin{tabular}{|c|c|c|c|c|c|c|}
\hline & \multicolumn{5}{|c|}{ PRONOMBRES } \\
\hline & \multicolumn{3}{|c|}{ Singular } & \multicolumn{3}{c|}{ plural } \\
\hline & 1. $^{\mathrm{a}} \mathrm{p}$. & $2 .^{\mathrm{a}} \mathrm{p}$. & $3 .^{\mathrm{a}} \mathrm{p}$. & $1 .^{\mathrm{a}} \mathrm{p}$. & $2 .^{\mathrm{a}} \mathrm{p}$. & $3 .^{\mathrm{a}} \mathrm{p}$. \\
\hline $\begin{array}{c}\text { en } \\
\text { castellano }\end{array}$ & yo & tú / usted & él, ella & nosotros & ustedes & ellos \\
\hline en kichwa & ñka & kan / kikin & Pay & ñukanchik & kikinkuna & Paykuna \\
\hline
\end{tabular}

Fuente: Elaboración propia

Tabla 9. Comparación de las partes de una conjugación en castellano y kichwa

\begin{tabular}{|c|c|c|c|c|}
\hline & & \multicolumn{3}{|c|}{ CONJUGACIÓN } \\
\hline & & \multirow[b]{2}{*}{$\begin{array}{c}\text { pronombre } \\
+\end{array}$} & \multirow[b]{2}{*}{$\begin{array}{c}\text { raíz verbal } \\
+\end{array}$} & \multirow{2}{*}{$\begin{array}{c}\text { terminaciones } \\
\text { verbales del } \\
\text { presente }\end{array}$} \\
\hline & & & & \\
\hline encastellano & \multirow{2}{*}{ 1. ${ }^{\mathrm{a}} \mathrm{p}$} & yo & camin & $\mathrm{O}$ \\
\hline \multirow[t]{11}{*}{ en kichwa } & & ñuka & puri & $\mathrm{Ni}$ \\
\hline & \multirow{2}{*}{ 2. ${ }^{\mathrm{a}} \mathrm{p}$} & tú / usted & camin & as /a \\
\hline & & kan / kikin & puri & Nki \\
\hline & \multirow{2}{*}{$3 .^{\mathrm{a}} \mathrm{p}$} & él / ella & camin & A \\
\hline & & pay & puri & $\mathrm{N}$ \\
\hline & \multirow{2}{*}{ 1. ${ }^{\mathrm{a}} \mathrm{p}$} & nosotros & camin & Amos \\
\hline & & ñukanchik & puri & Nchik \\
\hline & \multirow{2}{*}{ 2. ${ }^{\mathrm{a}} \mathrm{p}$} & ustedes & camin & an \\
\hline & & kikinkuna & puri & nkichik \\
\hline & \multirow{2}{*}{$3 .^{\mathrm{a}} \mathrm{p}$} & ellos & camin & an \\
\hline & & paykuna & puri & $\mathrm{n}$ \\
\hline
\end{tabular}

Fuente: Elaboración propia

\section{Conocer la estructura de una oración gramatical kichwa}

Los tres componentes que se encuentran en la estructura gramatical de una oración son sujeto, complemento, verbo $(\mathrm{S}+\mathrm{C}+\mathrm{V}+)$. Se llama sujeto a la persona, animal o cosa que realiza la acción del verbo; puede ser representada por pronombres, sustantivos o una estructura que cumple la función del núcleo. El predicado es el constituyente de la oración 
que ofrece información acerca del sujeto. Todos los elementos que hay en el predicado, a excepción del verbo, los llamamos complementos (Instituto de Idiomas, Ciencias y Saberes Ancestrales, 2016) (tabla 10):

Tabla 10. Comparación de una oración en castellano y kichwa

\begin{tabular}{|c|c|c|c|}
\hline & \multicolumn{3}{|c|}{ ORACIÓN } \\
\hline en castellano & $\mathrm{S}+$ & $\mathrm{V}+$ & $\mathrm{C}$ \\
\hline & Yo & soy & María \\
\hline en kichwa & $\mathrm{S}+$ & $\mathrm{C}+$ & $\mathrm{V}$ \\
\hline & Nuka & María & Kani \\
\hline
\end{tabular}

Fuente: Elaboración propia

El sujeto de una oración gramatical en el idioma kichwa será identificado con el morfema $k a$, el mismo que será pospuesto al pronombre, nombres propios o nombres comunes. El complemento será identificado con el uso del morfema mi, que en caso de usarse junto a otros morfemas siempre irá al final de la palabra base y después de cualquier otro morfema. El fin de su uso es afirmar, reafirmar o atestiguar la idea que se quiere transmitir, y es la razón por lo que se puede añadir o posponer al sujeto, complemento o verbo. Sin embargo, para el presente estudio se usará en el complemento para evitar confusiones (Cahuasquí, 2019b, sin publicar). Ejemplo de una correcta oración (tabla 11):

Tabla 11. Oración kichwa con morfemas $k a$ y $m i$

\begin{tabular}{|c|c|c|}
\hline $\mathrm{S}+$ & $\mathrm{C}+$ & $\mathrm{V}$ \\
\hline Ñukaka & María tiyami & kani \\
\hline
\end{tabular}

Fuente: Elaboración propia

\section{Conocer el sujeto}

Será identificado con el morfema $k a$, y tiene dos significados, entre otros:

1. Morfema $-k a$ usado con pronombres y nombres propios: en este caso el morfema $-k a$ no se traduce, simplemente es un identificador del sujeto (tabla 12). 
Tabla 12. Morfema $k a$ con pronombres y nombres propios

\begin{tabular}{|c|c|c|c|}
\hline & \multicolumn{3}{|c|}{$\begin{array}{c}\text { MORFEMA "KA" EN EL SUJETO } \\
\text { PRONOMBRES Y NOMBRES } \\
\text { PROPIOS }\end{array}$} \\
\hline \multirow[t]{2}{*}{ en kichwa } & $\mathrm{S}+$ & $\mathrm{C}+$ & $\mathrm{V}$ \\
\hline & Kikinka & Quito llaktapimi & kawsanki \\
\hline \multirow[t]{2}{*}{ en castellano } & $\mathrm{S}+$ & $\mathrm{V}+$ & $\mathrm{C}$ \\
\hline & Usted & vive & en Quito \\
\hline
\end{tabular}

Fuente: Elaboración propia

2. Morfema - $k a$ usado con nombres comunes: en este caso hace la función de sujeto y a la vez de artículos (el, la, los las) que el idioma kichwa no tiene en cuanto tal (tabla 14):

Tabla 13. Morfema $k a$ con nombres comunes

\begin{tabular}{|c|c|c|c|}
\hline \multirow{2}{*}{} & \multicolumn{3}{|c|}{$\begin{array}{r}\text { MORFEMA "KA" EN EL SUJETO } \\
\text { NOMBRES COMUNES }\end{array}$} \\
\hline en kichwa & $\mathrm{S}+$ & $\mathrm{C}+$ & $\mathrm{V}$ \\
\hline & Wasika & hatunmi & kan \\
\hline en castellano & $\mathrm{S}+$ & $\mathrm{V}+$ & $\mathrm{C}$ \\
\hline & La casa & es & grande \\
\hline
\end{tabular}

Fuente: Elaboración propia

\section{Conocer el complemento}

Cahuasquí (2019c, sin publicar) sostiene que el uso del morfema mi es indistinto; puede ir en el sujeto, complemento o verbo, por lo que se concluye que es un morfema enfatizador, pues se usa para afirmar, reafirmar o atestiguar la idea que se quiere transmitir a través de una palabra, expresión u oraciones gramaticales; sin embargo, se aconseja utilizar como identificador del complemento para evitar confusiones (tabla 14): 
Tabla 14. Morfema mi en la oración

\begin{tabular}{|c|c|c|c|}
\hline & \multicolumn{3}{|c|}{$\begin{array}{c}\text { MORFEMA "MI" ENFATIZADOR EN } \\
\text { EL SUJETO }\end{array}$} \\
\hline \multirow[t]{2}{*}{ en kichwa } & $\mathrm{S}+$ & $\mathrm{C}+$ & V \\
\hline & Paymi & Juan tiyu & kan \\
\hline \multirow[t]{3}{*}{ en castellano } & $\mathrm{S}+$ & $\mathrm{V}+$ & $\mathrm{C}$ \\
\hline & Él & Es & Juan \\
\hline & \multicolumn{3}{|c|}{$\begin{array}{l}\text { MORFEMA "MI" ENFATIZADOR EN } \\
\text { EL COMPLEMENTO }\end{array}$} \\
\hline \multirow[t]{2}{*}{ en kichwa } & $\mathrm{S}+$ & $\mathrm{C}+$ & V \\
\hline & Payka & Juan tiyumi & kan \\
\hline \multirow[t]{3}{*}{ en castellano } & $\mathrm{S}+$ & $\mathrm{V}+$ & $\mathrm{C}$ \\
\hline & Él & Es & Juan \\
\hline & \multicolumn{3}{|c|}{$\begin{array}{c}\text { MORFEMA "MI" ENFATIZADOR EN } \\
\text { EL VERBO }\end{array}$} \\
\hline \multirow[t]{2}{*}{ en kichwa } & $\mathrm{S}+$ & $\mathrm{C}+$ & V \\
\hline & Payka & Juan tiyu & kanmi \\
\hline \multirow[t]{2}{*}{ en castellano } & $\mathrm{S}+$ & $\mathrm{V}+$ & $\mathrm{C}$ \\
\hline & Él & Es & Juan \\
\hline
\end{tabular}

Fuente: Elaboración propia

Cabe recalcar que el uso del morfema $m i$ tiene un significado cultural muy importante que poco a poco se ha ido perdiendo de generación en generación. Anteriormente en la cultura kichwa el morfema $m i$ hacía relación a la verdad; la persona que usaba el morfema mi enfatizaba una palabra, una oración, una expresión mediante la cual quería destacar una verdad. Esto era así porque la palabra era como ley y como tal se debía cumplir. En la actualidad no se es consciente del significado trascendental del morfema mi. En caso de usar otros morfemas el mi siempre irá al final (tabla 15): 
Tabla 15. Morfema mi y morfema $p i$

\begin{tabular}{|c|c|c|c|}
\hline \multirow{2}{*}{} & \multicolumn{3}{|c|}{ MORFEMA "MI" ENFATIZADOR } \\
& \multicolumn{3}{|c|}{ CON OTRO MORFEMA } \\
\hline en kichwa & $\mathrm{S}+$ & $\mathrm{C}+$ & $\mathrm{V}$ \\
\hline & Juanka & Otavalo llaktapimi & kawsan \\
\hline en castellano & $\mathrm{S}+$ & $\mathrm{V}+$ & $\mathrm{C}$ \\
\hline & \multicolumn{3}{|c|}{ Juan vive en Otavalo } \\
\hline
\end{tabular}

Fuente: Elaboración propia

\section{Conocer el verbo}

El verbo será reconocido por las terminaciones propias de una conjugación y puede variar de acuerdo con el tiempo de conjugación (tabla 16):

Tabla 16. Conjugación del verbo (...) en diferentes tiempos

\begin{tabular}{|c|c|c|c|c|c|c|c|}
\hline \multicolumn{3}{|c|}{ PERSONA } & \multicolumn{5}{|c|}{ TIEMPO / PACHA } \\
\hline & & & PRESENTE & PASADO & P. PASADO & FUTURO I. & $\begin{array}{c}\text { FUTURO } \\
\text { M. }\end{array}$ \\
\hline $1^{\circ}$ & Ñuka & \multirow{3}{*}{ singular } & $\ldots+$ ni & $\ldots+$ rka + ni & $\ldots+$ shka + ni & $\ldots+\mathrm{kri}+\mathrm{ni}$ & $\ldots+$ sha \\
\hline $2^{\circ}$ & Kan/K. & & $\ldots+$ nki & $\ldots+$ rka + nki & $\ldots+$ shka + nki & $\ldots+\mathrm{kri}+\mathrm{nki}$ & $\ldots+$ nki \\
\hline $3^{\circ}$ & Pay & & $\ldots+n$ & $\ldots+$ rka & $\ldots+$ shka & $\ldots+\mathrm{kri}+\mathrm{n}$ & $\ldots+$ nka \\
\hline $1^{\circ}$ & Ñukanchik & \multirow{3}{*}{ plural } & $\ldots+$ nchik & $\ldots+$ rka + nchik & $\ldots+$ shka + nchik & $\ldots+$ kri + nchik & $\ldots+$ shun \\
\hline $2^{\circ}$ & Kikinkuna & & $\ldots+$ nkichik & $\ldots+$ rka + nkichik & $\ldots+$ shka + nkichik & $\ldots+$ kri + nkichik & $\ldots+$ nkichik \\
\hline $3^{\circ}$ & Paykuna & & $\ldots+\mathrm{n}$ & $\ldots+$ rka & $\ldots+$ shka & $\ldots+\mathrm{kri}+\mathrm{n}$ & $\ldots+$ nka \\
\hline
\end{tabular}

Fuente: Elaboración propia

Para el diseño de la propuesta de un aplicativo web se emplea una metodología especializada en el diseño de aplicaciones. El desarrollo de una aplicación, desde que se tiene la idea hasta que acaba en los dispositivos de los usuarios, se divide en varios pasos que pueden variar según el tiempo, el presupuesto y la cultura de la empresa. Conviene aclarar que no existe una manera correcta y formal de hacer una aplicación. La realidad es demasiado cambiante y debemos ser lo suficientemente rápidos para adaptarnos al mercado y ser nosotros los que creamos tendencia y no los que la seguimos (Montiel, 2017). 


\section{Materiales y métodos}

La estructura metodológica en el desarrollo de la investigación se orienta en función de los siguientes aspectos en orden descendente:

- La investigación cumple con los criterios de una investigación de carácter descriptiva no experimental, por lo que no se manipulan deliberadamente las variables. Las bases metodológicas del procedimiento utilizado corresponden al sustento de las herramientas y técnicas de la investigación. De acuerdo con el objetivo prefijado, la investigación se desarrolló durante los semestres lectivos 2018-2019, periodo donde se alcanzó una matrícula histórica de estudiantes para cursar el Kichwa I y II en la Universidad de Otavalo.

- El tipo de investigación efectuada determinó un estudio de campo, descriptivo, cualitativo y cuantitativo. Se consideró de campo porque se ejecutó un estudio minucioso, en la recopilación de información necesaria para el desarrollo del aplicativo web; descriptivo porque se determinó el criterio de estudiantes, así como las consideraciones de un profesor especialista en lengua kichwa; cualitativo porque se propone evaluar e interpretar información obtenida a través de recursos como entrevistas, y cuantitativo por el uso de herramientas estadísticas en el procesamiento de las encuestas para recabar los resultados.

- Se elaboró una encuesta según el consenso de expertos seleccionados por mediación de la prueba W de Kendall (Hurtado, 2007). Adicionalmente, se elaboró una entrevista cuyo patrón se centró en aspectos relevantes obtenidos por los autores, a través del análisis de documentos de información primaria y secundaria. El procesamiento estadístico de los resultados de la encuesta se efectuó básicamente mediante tablas de frecuencia y gráficos. Según información del Departamento de Secretaría Académica de la institución, los estudiantes que reciben la asignatura Kichwa I y II son en total 98. Las respuestas a las preguntas de la encuesta fueron todas medidas en una escala Likert de cinco alternativas de contestación. Se calcula el tamaño de muestra según la siguiente fórmula, que es la correspondiente a un muestreo probabilístico donde se requieren las proporciones de respuesta (Hernández, Fernández y Baptista, 2014).

$$
n=\frac{k^{2^{\wedge} *} p * q * N}{\left(e^{\wedge 2 *}(N-1)\right)+K^{\wedge 2 *} p * q}
$$


Los elementos de la fórmula son:

$\mathrm{n}=$ tamaño de la muestra buscado

$\mathrm{N}=$ tamaño de la población

$\mathrm{k}=$ parámetro estadístico que depende el nivel de confianza $(90 \%)$

e $=$ error de estimación máximo aceptado

$\mathrm{p}=$ probabilidad de que ocurra el evento estudiado (éxito)

$q=(1-p)=$ probabilidad de que no ocurra el evento estudiado

La encuesta estuvo conformada por ocho preguntas asociadas a la importancia que los estudiantes le conceden al uso de plataformas virtuales en la enseñanza de la lengua kichwa para estimular su aprendizaje y formación integral. Se utilizó el paquete estadístico SPSS versión 21. Fueron encuestados un total de 70 estudiantes de una población de 98. Fue conveniente para este estudio utilizar una confiabilidad de $95 \%$ para el cálculo del percentil correspondiente a la distribución normal, un error máximo permisible igual a 0.05 , mientras que la proporción muestral estimada, al no tener investigaciones anteriores que permitieran preestablecer este valor, fue considerada de $50 \%$, lo que además garantiza el máximo tamaño muestral. La fiabilidad de la encuesta medida a través del coeficiente alfa de Cronbach fue de 0.798 , por lo que puede considerarse alta.

Los 70 estudiantes encuestados son representativos de los 98 que están aprendiendo kichwa en la Universidad de Otavalo, garantizando que todos los estudiantes que se seleccionen al azar tengan iguales posibilidades de ser incluidos en la muestra obtenida.

La impartición de la asignatura Kichwa se organiza en seis grupos de estudiantes provenientes de comunidades urbanas y rurales del cantón Otavalo, Atuntaqui y Cotacahi, siendo estos los más significativos. Las edades de los alumnos oscilan entre 22 y 28 años. Los grupos poseen una composición étnica mixta, es decir, hay mestizos y estudiantes kichwa Otavalo, aunque se confronta la disyuntiva que siendo algunos de la etnia kichwa Otavalo, son muy pocos los que hablan su lengua materna, pero no la escriben y la gran mayoría no logra comunicarse, pero sí están interesados en dominarla, y existen 15 estudiantes kichwa Otavalo que dominan el inglés.

En la figura 1, se visualizan los resultados porcentuales según las preguntas de la encuesta. La importancia de impulsar el aprendizaje del kichwa en la Universidad de Otavalo está respaldada por el criterio de más de $70 \%$ de los estudiantes. Por otra parte, $39.1 \%$ se manifiesta neutral, condicionado por el desconocimiento de las bondades de un 


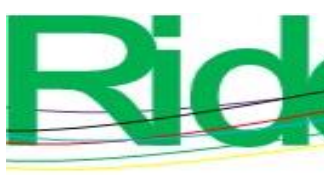

Revista Iberoamericana para la Investigación y el Desarrollo Educativo ISSN $2007-7467$

aplicativo web como material didáctico, que motiva el interés por el aprendizaje del idioma, con tecnologías de la información y las comunicaciones, aunque hay que destacar que las salas de clases de la universidad están dotadas con toda la tecnología necesaria para el uso de este recurso didáctico.

Sin embargo, cuando se indaga sobre la importancia del aplicativo web como herramienta para el aprendizaje, dentro de la institución la mayoría de los estudiantes (74\%) están de acuerdo o totalmente de acuerdo con su diseño, como herramienta con ventajas para el aprendizaje del idioma kichwa dentro y fuera de la institución. Por otra parte, $75 \%$ de los encuestados declaran que usarían un aplicativo web orientado al aprendizaje del idioma kichwa, y aproximadamente $77 \%$ lo manejaría porque consideran que contribuirá al aprendizaje y formación general de los estudiantes.

Hay que tener en cuenta el contexto intercultural y étnico del cantón Otavalo, cuna de la etnia kichwa Otavalo, donde se ubica la referida universidad, institución de educación superior bilingüe formadora de profesionales kichwa Otavalo, entre otros, encargados de valorizar su acervo cultural. En consecuencia, $74 \%$ de los estudiantes cree que si se implementa un aplicativo web para la enseñanza del idioma kichwa en la universidad, se contribuye al desarrollo de la nacionalidad kichwa. Teniendo en cuenta este análisis, se concluye que un aplicativo web para la enseñanza del idioma kichwa causa un impacto cultural de toda una nacionalidad que está dispersa en todo el país y contendrá la gramática kichwa unificada, que se obtendrá por la fundamentación teórica de varios autores y entidades gubernamentales que se suman a su proceso de aprendizaje (ver figura 1).

Para complementar la investigación se realizó una entrevista semiestructurada, considerándose que este tipo de instrumento ofrece un grado de flexibilidad aceptable, a la vez que mantiene la suficiente uniformidad para alcanzar interpretaciones acordes a los propósitos del estudio (Díaz, Torruco, Mildred y Varela, 2013). En concreto, se elaboró un cuestionario con cinco preguntas según la interrogante principal de investigación y el objetivo declarado, y se aplicó al director del Departamento de Idioma, profesional de alta experticia en la impartición de la docencia de idioma kichwa, perteneciente a la comunidad kichwa Otavalo y reconocido por la comunidad estudiantil y universitaria por sus trabajos investigativos presentados en eventos nacionales e internacionales. 
Figura 1. Resultados de la encuesta aplicada

Importancia aprendizaje kichwa.

70 respuestas

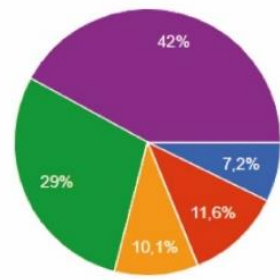

-1. Totalmente en

2. En desacuerdo

- 3. Neutral

4. De acuerdo

5. Totalmente de acuerdo
Existencia de aplicativo en U.O

70 respuestas



Uso de aplicativo web en aprendizaje kichwa.

70 respuestas

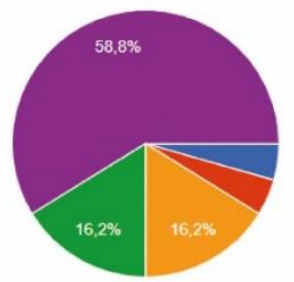

Contribución de un aplicativo web a la cultura kichwa.

70 respuestas

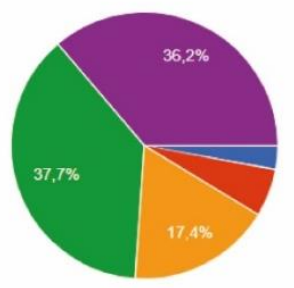

2. Creo que no

3. Tal vez

4. Creo que si

- 5. Si

2. creo que no

3. Tal vez

4. Creo ques

5. Si

\section{Existencia de materiales didácticos en U.O}

70 respuestas

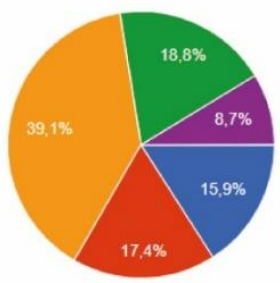

1. Totalmente en

-

- 2. En desacuer

3. Neutral

- 4. De acuerdo

5. Totalmente de acuerdo

Aplicativo web, herramienta aprendizaje kichwa

70 respuestas

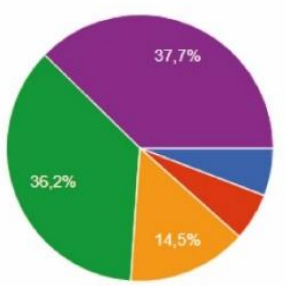

1. Totalmente en

desacuerdo

2. En desacuerdo

3. Neutral

- 4. De acuerdo

5. Totalmente de acuerdo

Contribución de un aplicativo web en enseñanza kichwa.

70 respuestas

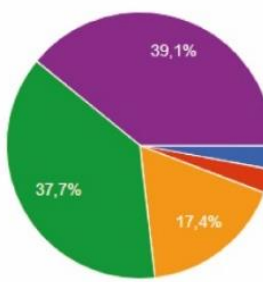

- 1. Totalmente en

2. En desacuerdo

3. Neutrat

3. Neutral

4. De acuerdo

5. Totalmente de acuerdo

Interes por aprender con aplicativo web, kichwa.

70 respuestas

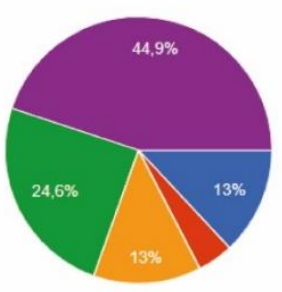

1. No

2. Creo que no

3. Tal vez

4. Creo que si

- $5 . \mathrm{SI}$

Fuente: Elaboración propia

Se determinó que la enseñanza del idioma kichwa en la Universidad de Otavalo, es necesaria debido a que la institución se declara desde sus inicios como intercultural, además está ubicada en una zona estratégica donde más de $50 \%$ de la población indígena 
habla el idioma kichwa, por lo que es importante que el estudiante domine la lengua debido a los servicios que brindarán en el futuro como profesionales.

Se declara, además, la ausencia de material didáctico como libros y cuadernos del aprendizaje del idioma kichwa, por lo que un material tecnológico como un aplicativo web definiría la secuencia lógica para el dominio de la lengua. Por otro lado, hace falta la ampliación de horas en la malla curricular de la asignatura Kichwa porque las 32 que se dictan en el semestre son insuficientes.

\section{Resultados}

\section{Proceso de diseño app}

Las fases de este proceso, desde la perspectiva del diseño y desarrollo, se han resumido en la figura 2:

Figura 1. Metodología aplicada de diseño

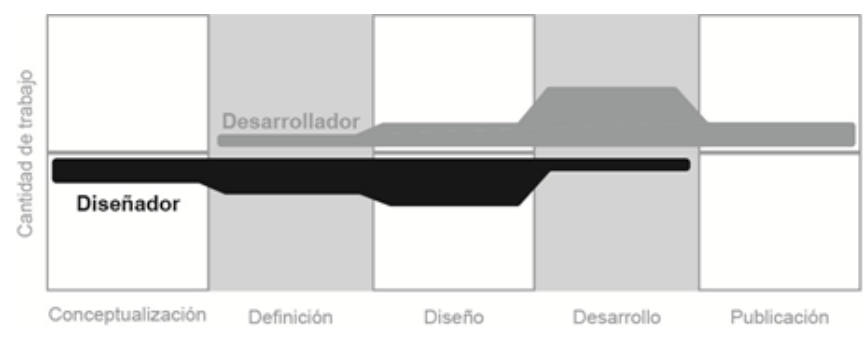

Fuente: Cuello y Vittones (2014)

Se utiliza la metodología especializada para aplicaciones de Cuello y Vittones (2014), la cual ha sido adaptada a esta investigación. El problema que resuelve se ajusta a la necesidad de cubrir la demanda de material didáctico interactivo para el aprendizaje del idioma kichwa, contribuyendo al mantenimiento de palabras que en esta lengua contienen significados culturales como costumbres, prácticas, rituales, maneras de ser, tipos de vestimenta y otros componentes que forman un tejido social llamado cultura.

\section{Formalización de la idea}

Al tener datos significativos del usuario se idearán las primeras funcionalidades de la aplicación, las cuales se dividen en dos fases: 


\section{Generación de hipótesis}

Gracias a algunas entrevistas con usuarios, sabemos que a la mayoría les frustra no conocer una aplicación web para el aprendizaje del idioma kichwa; por ende, creemos que diseñando una aplicación específica para el aprendizaje — con una interfaz de usuario que organice los contenidos académicos de una manera metafórica en la que se asocie lo cultural andino con la gramática kichwa para crear un concepto estético y fácil de comprender por cualquier tipo de usuario - ayudará al aprendizaje del idioma kichwa, además conseguiremos la aceptación y despertar el interés por la cultura kichwa.

\section{Esbozo y diseño conceptual}

Organización de los contenidos: Esta sección se refiere a la comprensión de los textos por medio de la legibilidad y la leibilidad. La correcta leibilidad se basa en el número de sílabas por palabra y el número de palabras por frase. Se usan párrafos que contengan pocas frases porque será más fácil de entender. Para la comprensión del texto se emplean títulos convenientes, argumentos lógicos y frases breves que estarán relacionadas al concepto de la aplicación. También se considerará la complejidad conceptual de los contenidos y su relación con la preparación del lector que los enfrentará.

Diseño centrado en el usuario: Esta sección se centra en el significante, significado y referente, signos lingüísticos que se unen en el cerebro para dar un enlace asociativo.

Pictogramas: Esta sección se concentra en el diseño de símbolos gráficos para la información y operación del aplicativo web. El diseño de símbolos para información del público requiere que el significado de los símbolos sea evidente sin mediar un aprendizaje. Por eso, se usarán íconos diseñados y establecidos a lo largo de la era digital que facilitarán el proceso cognitivo de los usuarios.

\section{Definición de usuarios}

En esta etapa se definen modelos o arquetipos de usuarios para los cuales se diseña teniendo en cuenta sus necesidades y objetivos. Se usa la herramienta llamada persona, que consiste en una representación singular y ficticia de un segmento clave del público objetivo. Tendrá una cara, nombre, historia, necesidades y objetivos. 


\section{Definición funcional}

Todas las acciones e interacciones que hacen falta para que un usuario consiga su objetivo se traducen en funciones que debe tener la aplicación. Con el viaje del usuario se pueden detectar cuáles son las necesidades que tiene en cada etapa y cuáles herramientas requiere para poder avanzar a la siguiente.

\section{Test de usuarios}

El test que se eligió para obtener información de los usuarios fue un test guerrilla, que consiste en reunir a una determinada cantidad de personas para probar la aplicación con el objetivo principal de ver cómo se comportan y recabar datos que permitan corregir errores.

El número de voluntarios fue de cinco a ocho personas, pues con esta cantidad se puede detectar casi la totalidad de problemas más comunes de usabilidad. El lugar donde se llevó a cabo fue en las aulas de la Universidad de Otavalo, porque es un sitio tranquilo, dotado de pizarras digitales, donde no hay interrupciones y es el escenario más realista donde se usará la aplicación. En anexos se agrega el diseño visual y funcional del aplicativo web para el aprendizaje del idioma kichwa (ver anexos I-XX).

\section{Discusión}

El idioma es el corazón viviente de una cultura. Históricamente, en el sistema público de educación del Ecuador no se han tenido en cuenta las lenguas ancestrales. La creación de la Dirección Nacional de Educación Intercultural Bilingüe, amparada en el Registro Oficial n. ${ }^{\circ} 278$ de 17 septiembre del 1993, impuso la toma de conciencia respecto a las lenguas patrimoniales de las diferentes nacionalidades ecuatorianas. La enseñanza de idiomas ancestrales, en este caso el kichwa, ha tenido debilidades en su concepción metodológica, pues no se ha tenido la experiencia de tratarlas en un ambiente escolarizado y tampoco han ingresado al ámbito de la lectoescritura de la misma manera que los idiomas que tienen una larga tradición en este campo (Calderón, 2012; Contreras, 2010).

El contexto actual, caracterizado por una acumulación mayor de posiblidades de acceso masivo a un más amplio cúmulo de conocimientos producidos por el hombre, se identifica por la capacidad de buscar, sistematizar, comprender, organizar y principalmente utilizar la información a la que se accede por medio de las tecnologías para producir nuevos saberes, y que los pueblos puedan contar con herramientas 
cognitivas y competencias que permitan accionar de modo crítico, creativo, reflexivo y responsable sobre la abundancia de datos para aplicarlo a diversos contextos y entornos de aprendizaje, así como para construir conocimiento relevante con base en ellos (Aguerrondo, Grinberg, Lugo, Marchesi y Ortega, 2006).

Según Vallejo (2010), un proceso de integración de tecnologías de la información en la educación se orienta a aristas como la educativa, formando a los niños, jóvenes y docentes en nuevos entornos de aprendizaje y cooperación; de integración territorial, con el establecimiento de una infraestructura pública de redes que articulen a la comunidad local en instancias provinciales, nacionales, regionales y globales; de modernización administrativa, informatizando la comunicación, la administración y la gestión de los organismos centrales, zonales y de las instituciones escolares; de desarrollo social, con la constitución de nuevos espacios y oportunidades de aprendizaje para distintos públicos a través de la formación continua y la recalificación profesional/laboral mediante la educación a distancia y la conformación de comunidades virtuales de aprendizaje. Por tanto, esta propuesta del análisis se apoya sobre las bases de la incorporación de las TIC en la educación como parte componente de una política integral del Estado, que también involucra a los ámbitos de la salud, seguridad social, justicia, trabajo y cultura, entre otros (Guerrero y Dotes, 2012).

La propuesta de un aplicativo web nace por la necesidad de preservar y aprender un idioma ancestral. Sin embargo, en la investigación se manifestaron limitaciones motivadas por el desconocimiento de metodologías y técnicas informáticas adecuadas en el aprendizaje del kichwa. Además, y a pesar de que en la Universidad de Otavalo se imparte como asignatura desde el 2004, no se aprecia evidencia alguna del uso de estas en el proceso docente; por tal motivo, la incorporación al proceso de enseñaza y aprendizaje del aplicativo diseñado, y según los resultados de la encuesta a los estudiantes, tendrá un impacto sociocultural de trascesdencia nacional este tipo de iniciativas despierta el interés por cultivarse, incluso si el estudiante o persona no forma parte de una institución bilingüe. Aunado a esto, se facilita el flujo de aprendizaje por el empleo de recursos multimedia que despiertan el interés, la motivación y la atención en tanto cubre la demanda de material didáctico interactivo para el aprendizaje del idioma kichwa en instituciones educativas bilingues.

El aplicativo web para el aprendizaje del idioma kichwa unificado tiene como fortaleza su utilidad metodológica, ya que se podrán realizar futuras investigaciones que utilicen metodologías compatibles, de manera que se efectuarán análisis conjuntos entre 
instituciones e investigadores relacionados con la temática de comparaciones entre periodos temporales concretos y evaluaciones que se estuvieran llevando a cabo para el aprendizaje del idioma kichwa.

\section{Conclusiones}

El aplicativo web demuestra que su uso contribuye a la valorización del aprendizaje del idioma kichwa y que se pueden crear materiales didácticos en distintas plataformas con la colaboración de un equipo de trabajo que cubrirá todas las fases de preproducción, producción y posproducción.

Para ello, por supuesto, resulta esencial la correcta organización de información gramatical de la referida lengua. Luego el estudiante - al culminar sus horas de estudio que impone la malla curricular de la institución- podrá usar el aplicativo web en su tiempo libre durante 30 minutos al día, lapso suficiente para adquirir la "memoria de trabajo" útil para el aprendizaje. Si se calculan los minutos por semana, se obtiene como resultado 3:30 horas más las horas de estudio de la universidad son 5:30 horas. Esta es la estimación mínima, ya que el aplicativo puede emplearse sin límite de tiempo, de ahí que la variante principal recaiga en el interés del estudiante.

Se tiene el criterio por parte de los investigadores que diseñando una aplicación específica para el aprendizaje con una interfaz de usuario que organice los contenidos académicos de una manera metafórica, en la que se asocie lo cultural andino con la gramática kichwa para crear un concepto estético y fácil de comprender por cualquier tipo de usuario, ayudará al aprendizaje del idioma, y se logrará la aceptación y despertar el interés por esa cultura en las nuevas generaciones.

Afrontar alternativas de mejora académica, considerando la inclusión educativa y el efecto en el aprendizaje de la lengua kichwa de los pueblos andinos, provoca el repensar en futuras investigaciones por la defensa y sostenibilidad de las expresiones de las culturas nacionales ancestrales (autóctona), pues representa un caudal de conocimientos patrimoniales que se deben proteger; de lo contrario, se estará dando lugar a pobres niveles de cohesión social y pérdida de las tradiciones, cultura e identidad sociocomunitaria. 


\section{Agradecimiento}

A la Universidad de Otavalo, Departamento de Idiomas, docentes, estudiantes y personal administrativo por su contribución a que esta investigación llegara a feliz término.

\section{Referencias}

Adobe (2020). Diseña como siempre imaginaste hacerlo. Recuperado de https://www.adobe.com/la/products/xd.html

Aguerrondo, I., Grinberg, S., Lugo, M., Marchesi, A. y Ortega, M. (2006). La integración de las tecnologías de la información y la comunicación en los sistemas educativos. Buenos Aires: Unesco. Recuperado de https://unesdoc.unesco.org/ark:/48223/pf0000150785.locale=es

Alvarez, C. y Montaluisa, L. (2017). Perfiles de las lenguas y saberes del Ecuador. Quito: La Guaragua.

Buitrón, B. A. (2019). Diseño de un aplicativo web para el aprendizaje del idioma kichwa (tesis de grado). Otavalo, Imbabura, Ecuador: Universidad de Otavalo.

Calderon, F. (2012). Apoyo metodológico para la enseñanza de la lengua kichwa a través del arte en el Colegio Técnico Intercultural Chakiñan, extensión Quito (tesis de licenciatura). Pontificia Universidad Católica del Ecuador, Quito. Recuperado de http://repositorio.puce.edu.ec/handle/22000/7254

Camas, M. (2016). Estrategias metodológicas para fortalecer el aprendizaje de la lengua kichwa, en el décimo grado de la EGB de la Unidad Educativa Comunitaria Intercultural Bilingüe Quilloac, en el año lectivo 2016-2017 (tesis de grado). Universidad Politécnica Salesiana. Recuperado de http://dspace.ups.edu.ec/handle/123456789/13233

Constitución Política de la República del Ecuador (2008). Constitución Política de la República del Ecuador. Montecristi: Asamblea Constituyente.

Contreras, E. (2010). Manual de metodologías de enseñanza de lenguas. Quito: Ecuador. Recuperado de https://educacion.gob.ec/wpcontent/uploads/downloads/2013/03/RK_manual_ensenanza_lenguas.pdf

Cuello, J. y Vittones, J. (2014). Dseñando apps para móviles. Bogotá (Colombia): Ed. Catalina Duque Giraldo

Díaz, L., Torruco, U., Martínez, M. y Varela, R. (2013). La entrevista, recurso flexible y dinámico. Investigación en Educación Médica, 2(7), 162-167. Recuperado de https://www.redalyc.org/articulo.oa?id=3497/349733228009 
Gómez, M., Zalba, E., Arenas, N., Mabel, F., Párraga, C. y Gantus, V. (2005) Gramática para todos (1 ${ }^{\text {a }}$ ed.). Mendoza: EDIUNC.

Guerrero, M. y Dotes, F. (2012). Integración curricular de TIC'S en la enseñanza de lenguas indígenas en Latinoamerica. Revista Electrónica Diálogos Educativos, (22), 24-25.

Hernández, R., Fernández, R. y Baptista, L. (2014). Metodología de la investigación (6. ${ }^{\mathrm{a}}$ ed.). Mexico: Mc Graw Hill. Recuperado de http://observatorio.epacartagena.gov.co/wpcontent/uploads/2017/08/metodologia-de-la-investigacion-sextaedicion.compressed.pdf

Hurtado, S. (2007). Criterio de expertos. Su procesamiento a través del método Delphy. HIstodidáctica. http://www.ub.edu/histodidactica/index.php?option=com_content\&view=article \&id=21:criterio-de-expertos-su-procesamiento-a-traves-del-metododelphy\&catid=11\&Itemid=103

Ilvis, M. (2018). El aprendizaje del idioma kichwa y el fortalecimiento de la inclusión educativa en 10mo año de educación general básica de la Unidad Educativa Comunitaria Intercultural Bilingüe Guardiana de la Lengua y los Saberes Santiago de Guayaquil. Universidad Laica Vicente Rocafuerte de Guayaquil. Recuperado de http://repositorio.ulvr.edu.ec/handle/44000/3292

Instituto de Idiomas, Ciencias y Saberes Ancestrales (2016). Kichwa Yachakukunapa Shimiyu Кати. Quito: Medios Públicos E.P.

Instituto Nacional de Estadísticas y Censo (INEC), (2010). Recuperado de: https://www.ecuadorencifras.gob.ec/base-de-datos-censo-de-poblacion-yvivienda-2010/

Lema, S. (1997). Gramática quichua: didáctica de la lengua quichua con las últimas reformas de la Real Academia lingüística: un valor, una cultura, una expresión. Quito (Ecuador): Abya-Yala. Recuperado de https://digitalrepository.unm.edu/cgi/viewcontent.cgi?article $=1437 \&$ context=ab ya_yala

Mejeant, L. (2001). Culturas y lenguas indígenas del Ecuador. Revista Yachaikuna. Recuperado de http://icci.nativeweb.org/yachaikuna/1/mejeant.pdf 
Mendoza, M. y Barrios, J. (2004). Propuestas metodológicas para el desarrollo de aplicaciones Web: una evaluación según la ingeniería de métodos. Revista Ciencia e Ingeniería, 25(2), 89-96.

Ministerio de Educación de Ecuador (2009). Kichwa yachakukkunapa Shimiyuk Kamu. Quito: Gobierno de la República del Ecuador.

Montiel, A. (2017). El mobile marketing y las apps: cómo crear apps e idear estrategias de mobile marking. Barcelona: Editorial UOC.

Oficina Regional de Educación para América Latina y el Caribe (2013). Enfoque Estratégicos Sobre las TICS en Educación en América Latina y El Caribe. Chile: OREAL/UNESCO Santiago. Recuperado de http://www.unesco.org/new/fileadmin/MULTIMEDIA/FIELD/Santiago/images/ ticsesp.pdf

Organización Internacional del Trabajo [OIT] (2014). C169-Convenio sobre pueblos $\begin{array}{lllll}\text { indigenas } & y & \text { tribales, } & \text { 1989. }\end{array}$ https://www.ilo.org/dyn/normlex/es/f?p=NORMLEXPUB:12100:0::NO::P1210 0_ILO_CODE:C169

Paza, M. (2011). Kichwa Shimita Yachanakamu. Quito: Tinkunakuy.

Pérez, J. y Merino, M. (2017). Definicion de alfabeto. Recuperado de https://definicion.de/alfabeto/

Pichazaca, L. (2017). Causas que inciden en la pérdida del idioma Kichwa en el CECIB Miguel Ignacio Cordero Moncayo de la comunidad de Cahuazhun Grande (tesis de grado). Ecuador: Universidad Politécnica Salesiana. Recuperado de http://dspace.ups.edu.ec/handle/123456789/15301

Quispe Yucra, J., Urrelo Valdivia, M., Morales Muraña, A. y Cariman Davis, A. (2012). Programa de estudio tercer año básico. Sector lengua indígena quechua. Santiago, Chile: Ministerio de Educación.

Rodríguez, M. (2018). Educación intercultural bilingüe, interculturalidad y plurinacionalidad en el Ecuador. Quito: Abya-Yala.

Rojas, F. y Bolivar, J. (2009). Autoconcepto estudiantil y modalidades de enseñanza a distancia (B-learning y E-learning). Paradigma, 30(2), 99-111. Recuperado de http://ve.scielo.org/scielo.php?script=sci_arttext\&pid=S101122512009000200007 
Salinas, J. (1997). Nuevos ambientes de aprendizaje para una sociedad de la información.

Revista Pensamiento Educativo, 20, 81-104. Recuperado de https://www.ses.unam.mx/curso2008/pdf/Salinas.pdf

Sunkel, G. y Trucco, D. (2012). TIC para la educación en América Latina: hacia una perspectiva integral. Recuperado de http://www.relpe.org/especial-del-mes/ticpara-la-educacion-en-america-latina-hacia-unaperspectiva-integral/

Vallejo, R. (2010). Manual de metodologías de enseñanza de lenguas. Ministerio de Educación de Ecuador. Recuperado de https://educacion.gob.ec/wpcontent/uploads/downloads/2013/03/RK_manual_ensenanza_lenguas.pdf

Yachakukkunapa Shimiyuk Kamu (2009). Diccionario escolar intercultural bilingüe de las lenguas ancestrales. Ministerio de Educación, Colección Runa Kay. 


\begin{tabular}{|c|c|}
\hline Rol de Contribución & Autor (es) \\
\hline Conceptualización & Alberto Cahuasquí \\
\hline Metodología & Alberto Cahuasquí \\
\hline Software & NO APLICA \\
\hline Validación & Alberto Cahuasquí \\
\hline Análisis Formal & NO APLICA \\
\hline Investigación & Alberto Cahuasquí \\
\hline Recursos & Alberto Cahuasquí \\
\hline Curación de datos & NO APLICA \\
\hline $\begin{array}{l}\text { Escritura - Preparación del } \\
\text { borrador original }\end{array}$ & Alberto Cahuasquí \\
\hline $\begin{array}{l}\text { Escritura - Revisión y } \\
\text { edición }\end{array}$ & Alberto Cahuasquí \\
\hline Visualización & NO APLICA \\
\hline Supervisión & Alberto Cahuasquí \\
\hline $\begin{array}{l}\text { Administración de } \\
\text { Proyectos }\end{array}$ & Alberto Cahuasquí \\
\hline Adquisición de fondos & NO APLICA \\
\hline
\end{tabular}




\section{ANEXOS}

Anexo 1. Pantalla de inicio

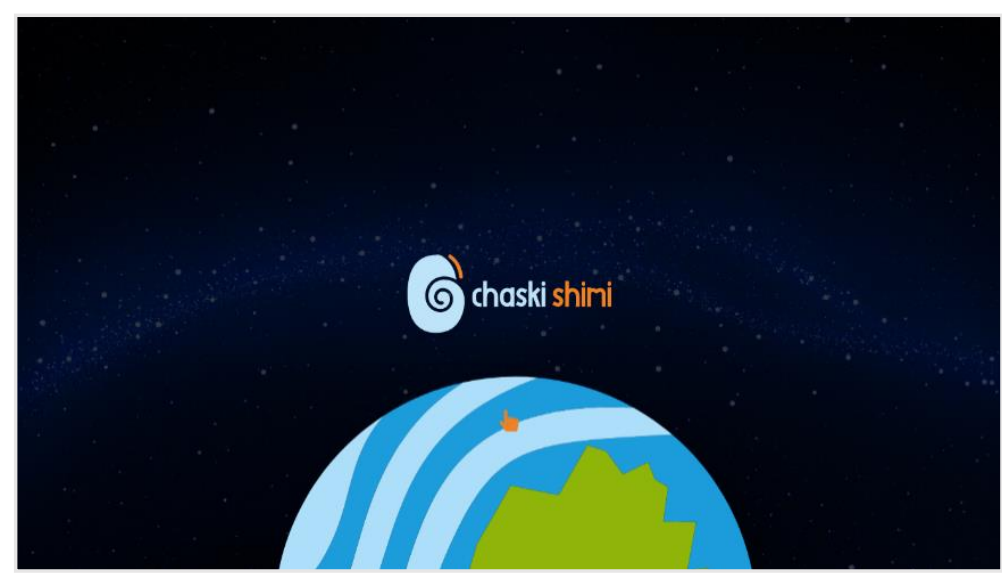

Fuente: Elaboración propia

Anexo 2. Portal I

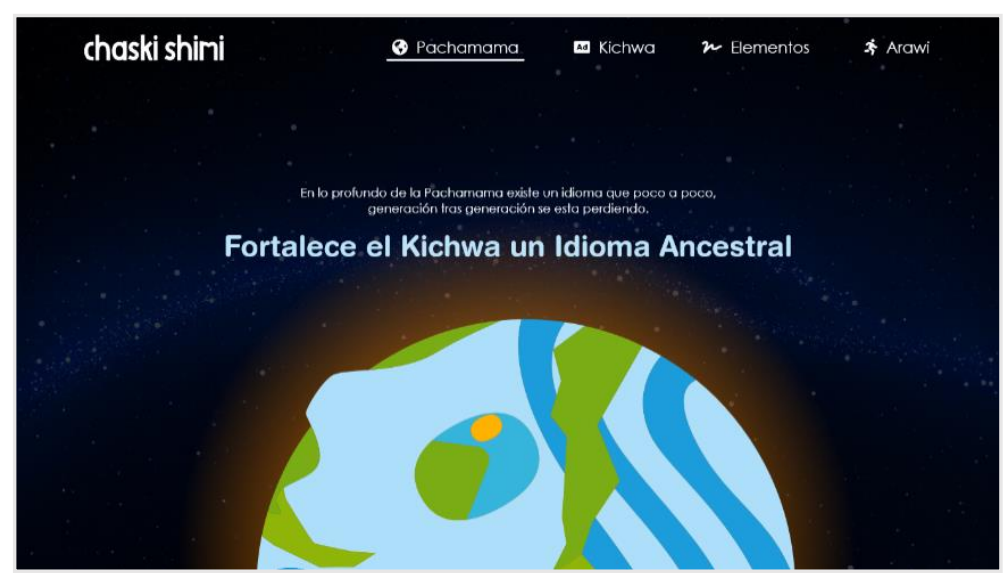

Fuente: Elaboración propia

Anexo 3. Ventana kichwa

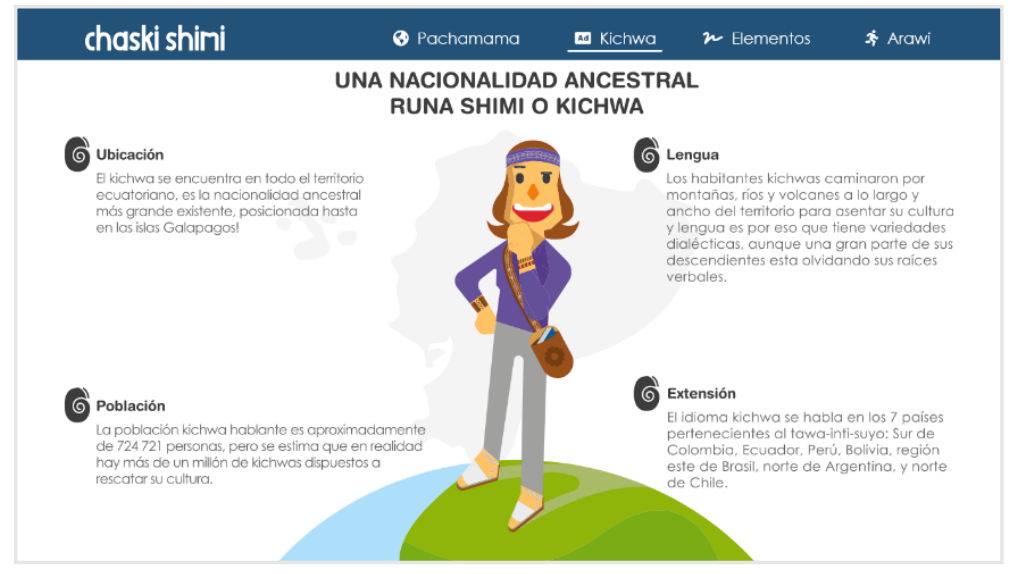

Fuente: Elaboración propia 
Revista Iberoamericana para la

Investigación y el Desarrollo Educativo

ISSN 2007 - 7467

Anexo 4. Ventana Elementos

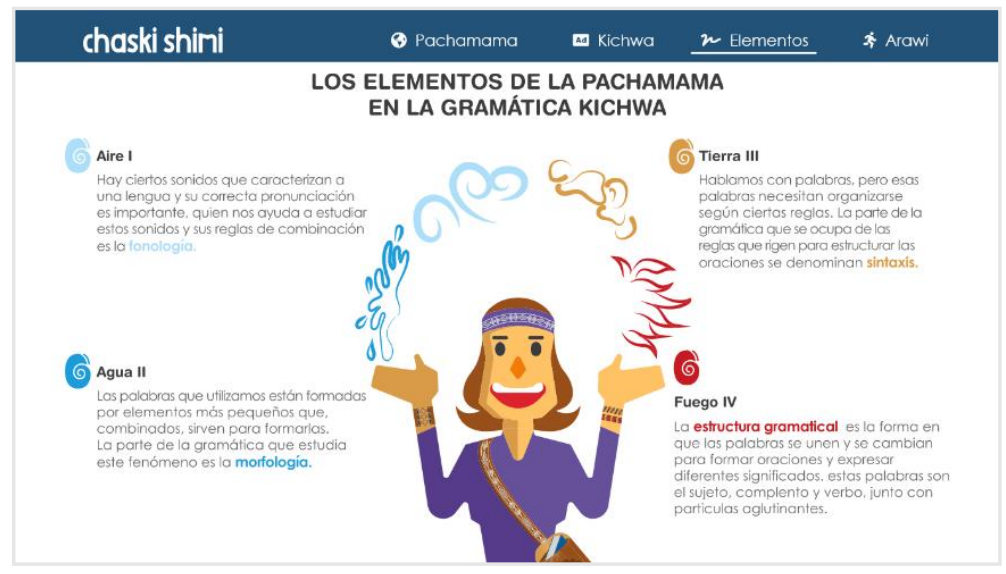

Fuente: Elaboración propia

Anexo 5. Ventana Arawi

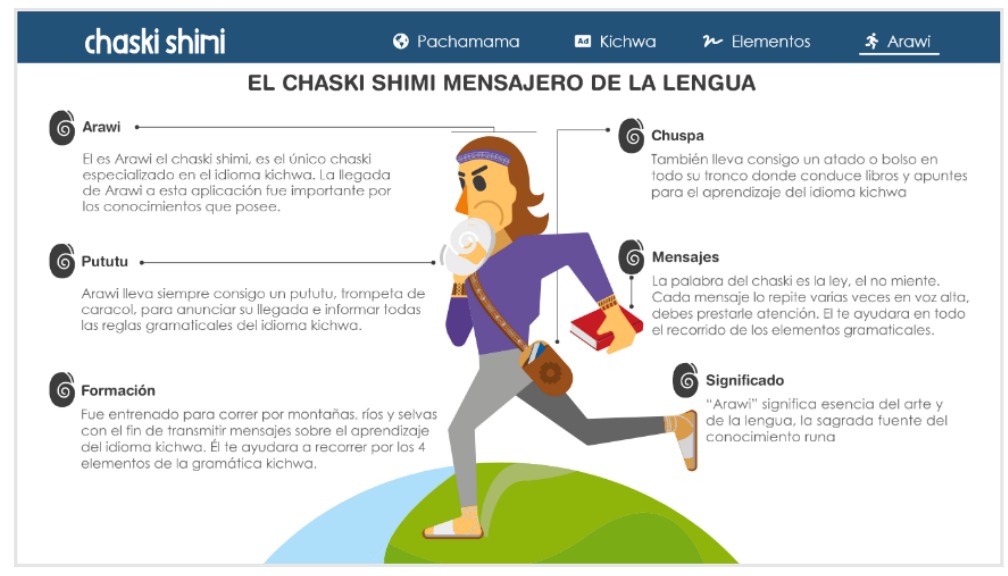

Fuente: Elaboración propia

Anexo 6. Pop Up

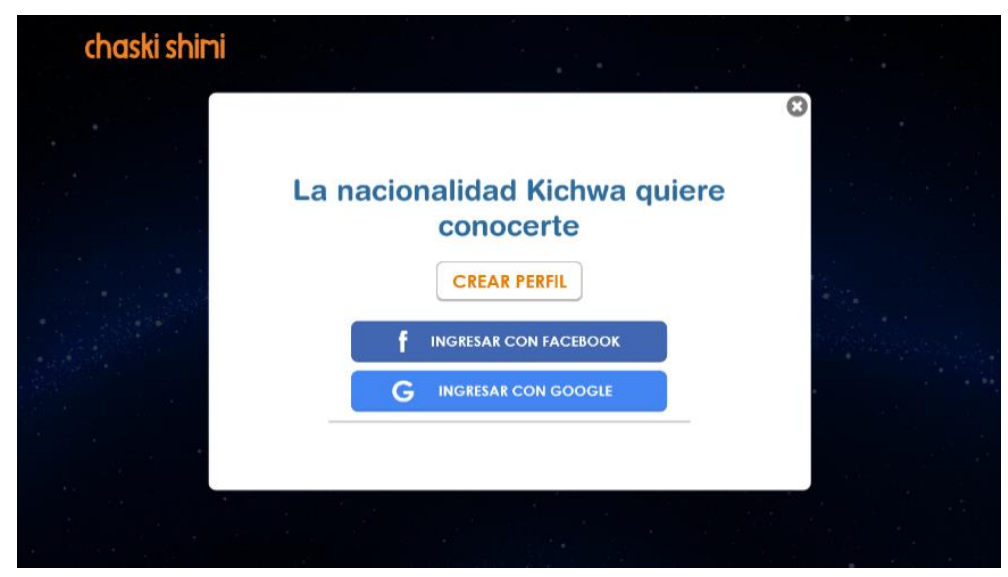

Fuente: Elaboración propia 
Revista Iberoamericana para la Investigación y el Desarrollo Educativo

Anexo 7. Recorrido interfaz gráfica

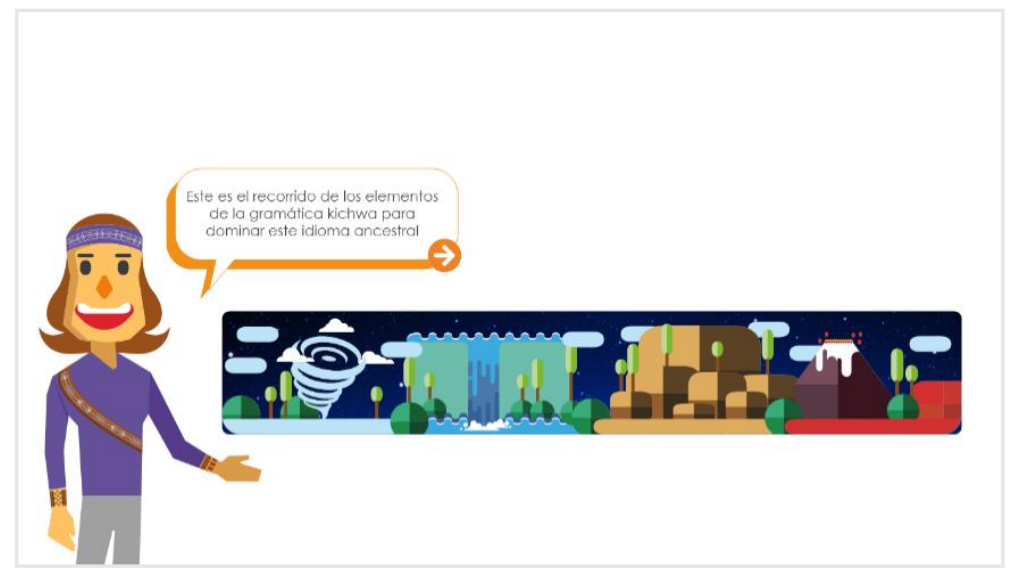

Fuente: Elaboración propia

Anexo 8. Recorrido interfaz gráfica

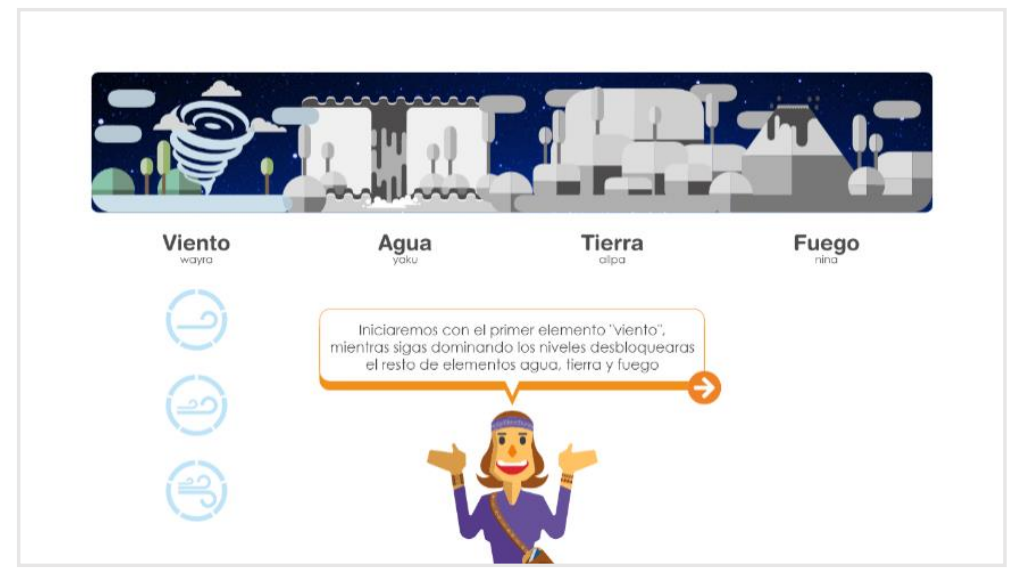

Fuente: Elaboración propia

Anexo 9. Recorrido interfaz gráfica

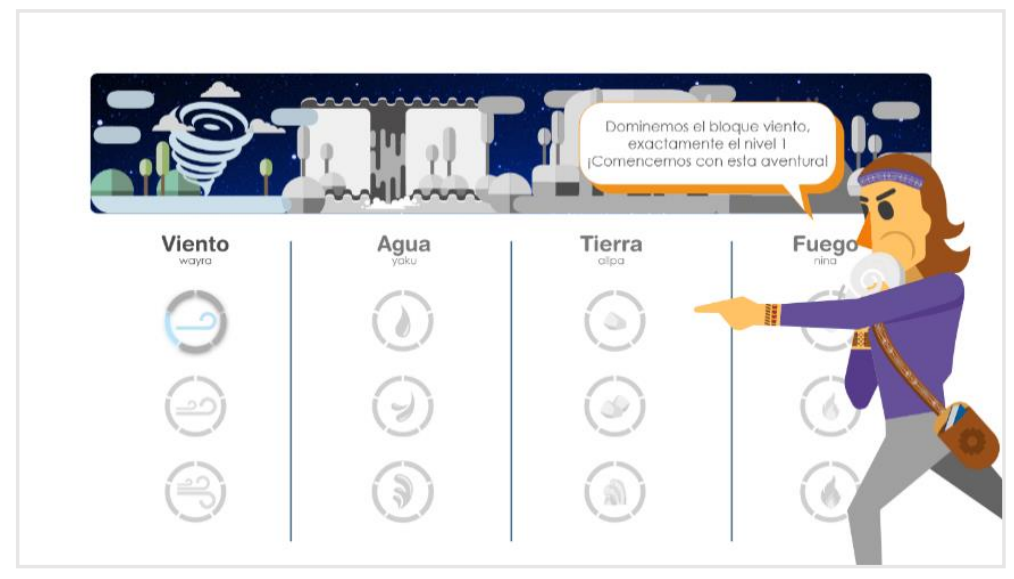

Fuente: Elaboración propia 
Anexo 10. Portal II

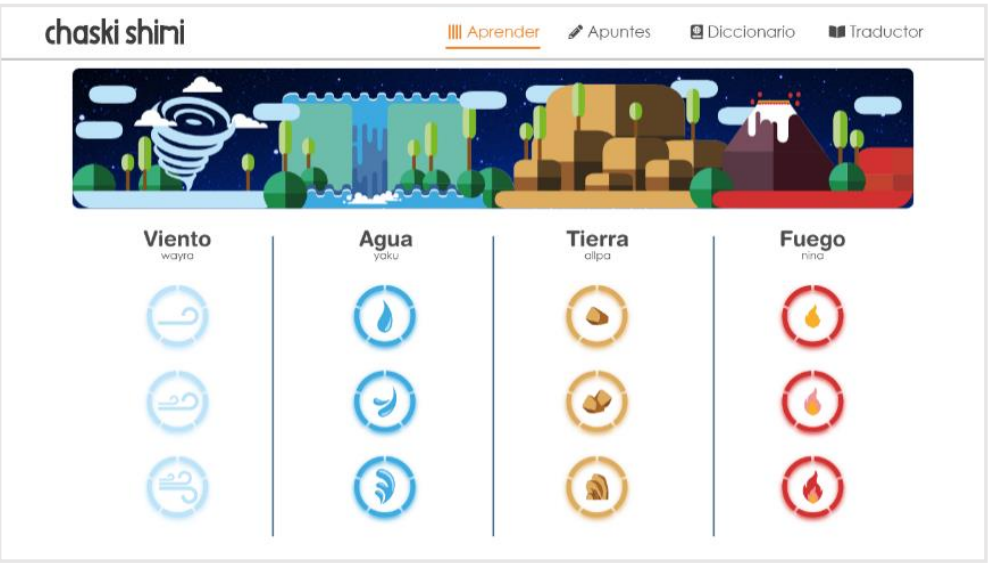

Fuente: Elaboración propia

Anexo 11. Inicio de ejercicios

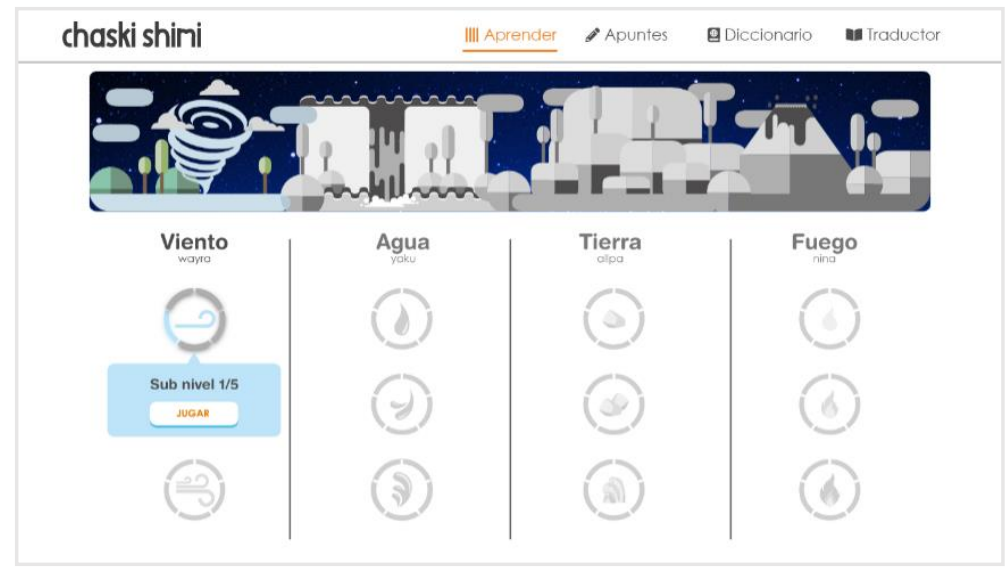

Fuente: Elaboración propia

Anexo 12. Ejercicio 1

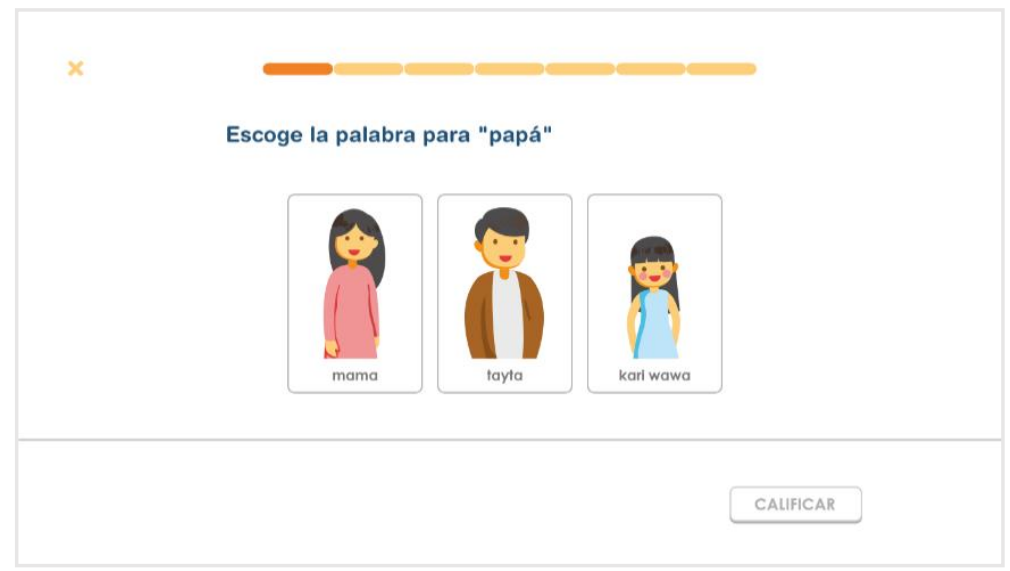

Fuente: Elaboración propia 
Anexo 13. Ejercicio 1 (incorrecto)

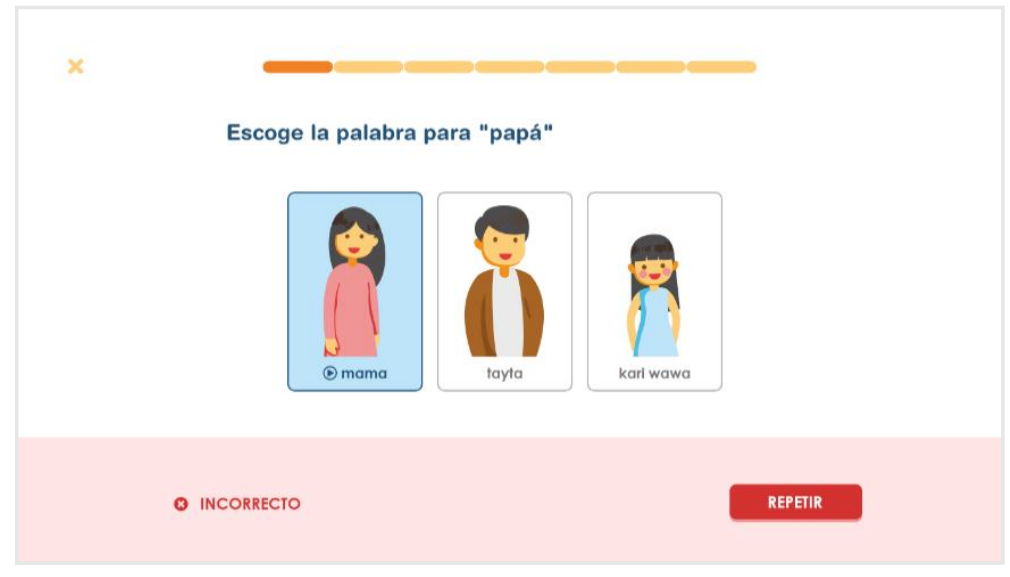

Fuente: Elaboración propia

Anexo 14. Ejercicio 1 (correcto)

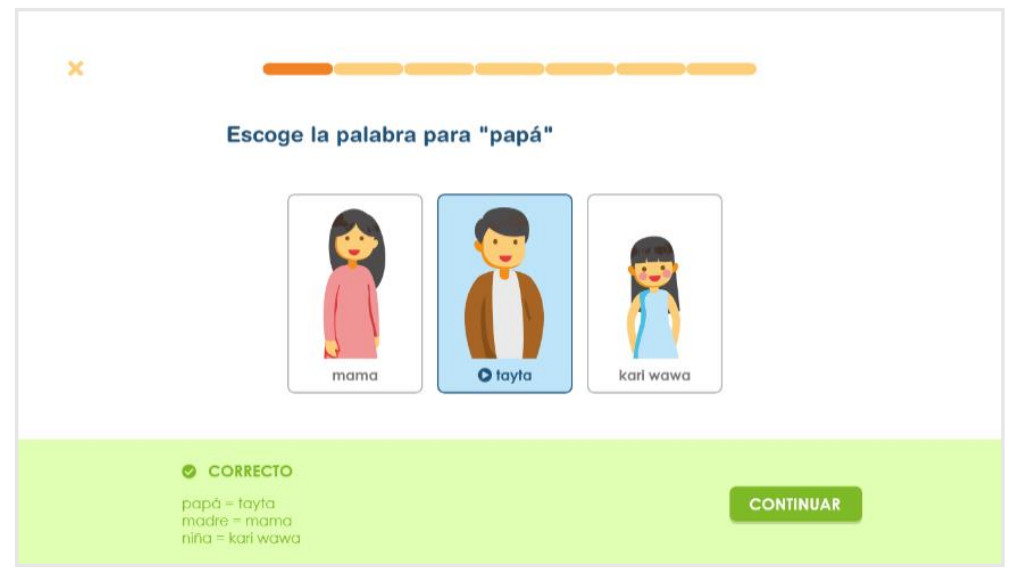

Fuente: Elaboración propia

Anexo 15. Ejercicio 3

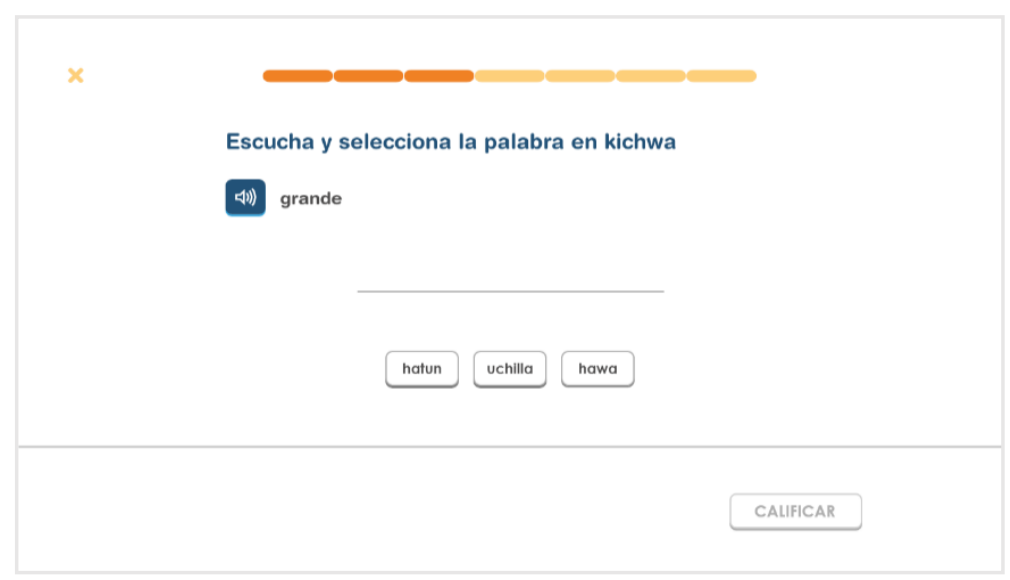

Fuente: Elaboración propia 
Anexo 16. Ejercicio 3 (correcto)

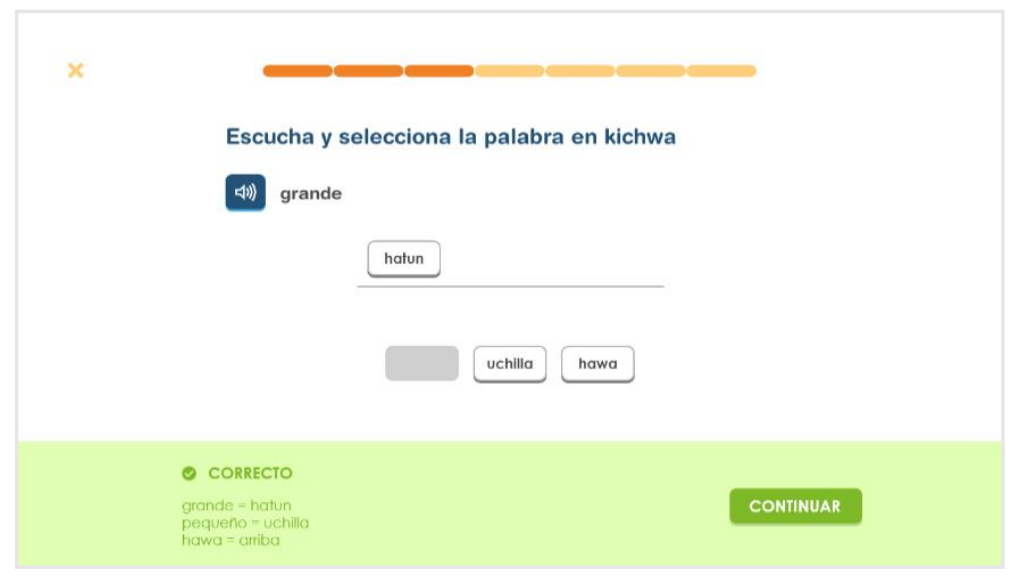

Fuente: Elaboración propia

Anexo 17. Ejercicio 3 (incorrecto)



Fuente: Elaboración propia

Anexo 18. Ejercicio 7 (retroalimentación)

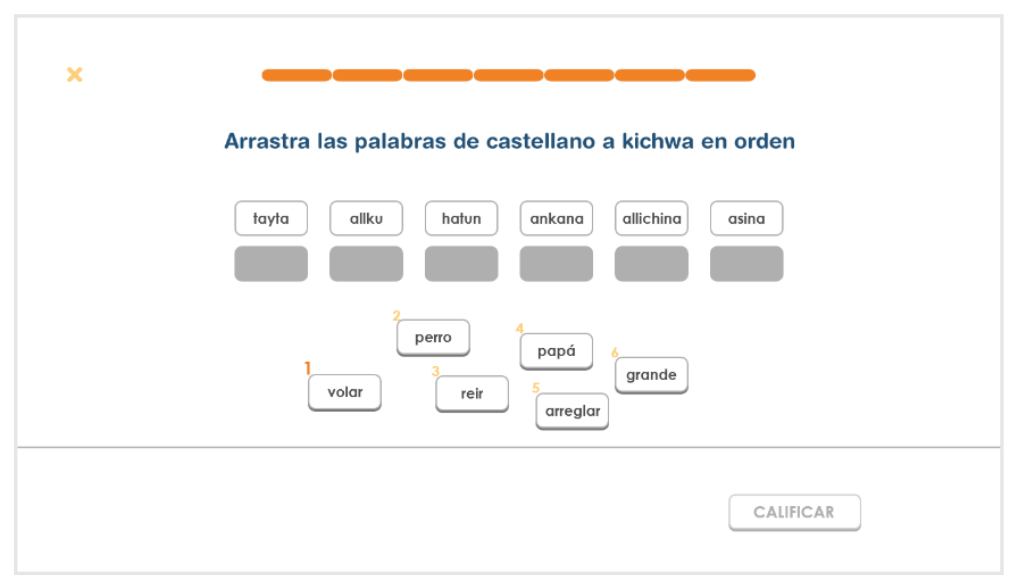

Fuente: Elaboración propia 
Anexo 19. Ejercicio 7 (retroalimentación correcto)

Arrastra las palabras de castellano a kichwa en orden

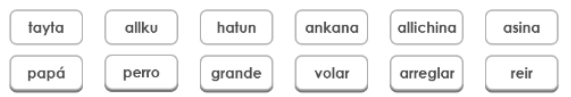

Fuente: Elaboración propia

Anexo 20. Fin de ejercicios

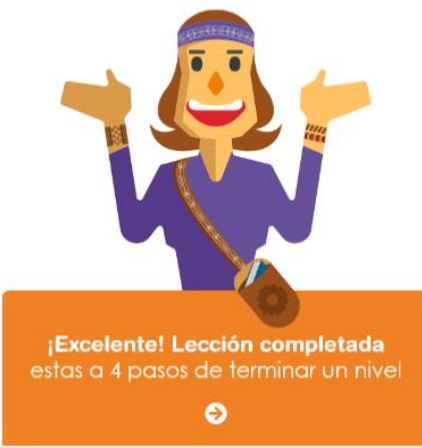

Fuente: Elaboración propia 